\title{
Preparation and characterization of novel thermoset polyimide and polyimide-peo doped with $\mathrm{LiCF}_{3} \mathrm{SO}_{3}$
}

\author{
M. H. Ŭgur, R. D. Toker, N. Kayaman-Apohan, A. Güngör* \\ Marmara University, Department of Chemistry, 34722 Istanbul, Turkey
}

Received 29 July 2013; accepted in revised form 14 October 2013

\begin{abstract}
This paper deals with the synthesis and characterization of a new type of anhydrous ionic conducting lithium doped membranes consist of polyimide (PI), poly (ethylene oxide) (PEO) and lithium trifluoromethanesulfonate $\left(\mathrm{LiCF}_{3} \mathrm{SO}_{3}\right)$ for solid polymer electrolyte (SPE). For this purpose, different molar ratios of lithium salt (Li-salt) solution are added into poly (amic acid) (PAA) intermediate prepared from the reaction of 3,3',4,4'-benzophenon tetracarboxylic dianhydride (BTDA) and 4,4'-oxydianiline (ODA). PEO is incorporated into PAA since it forms more stable complexes and possess high ionic conductivities. Then, Li-salt containing PAA solutions are imidized by thermal process. The effect of interaction between host polymer and Li-salt is characterized by FT-IR (Fourier Transform Infrared) spectroscopy and SEM (scanning electron micrsocopy). The conductivities of Li-salt and PEO containing PI composite membranes are in the range of $10^{-7}-10^{-5} \mathrm{~S} \cdot \mathrm{cm}^{-1}$. The conductivity increases with incorporation of PEO. Thermogravimetric analysis results reveal that the $\mathrm{PI} / \mathrm{PEO} / \mathrm{LiCF}_{3} \mathrm{SO}_{3}$ composite polymer electrolyte membranes are thermally stable up to $500^{\circ} \mathrm{C}$.
\end{abstract}

Keywords: polymer composites, polymer membranes, ionic conductivity

\section{Introduction}

Polyimides (PIs) belong to the important class of polymeric materials known as 'high performance' polymers due to their high thermo-oxidative stability [1], their exceptional mechanical properties, good film forming ability and superior chemical resistance [2-6]. Although, high performance polyimides are widely used in the microelectronics industry because the imide rings may provide permittivities equivalent to those of high dielectric constant to materials [7]. Work on polymer/salt mixtures has increased during recent years due to the growing interest in these systems as fast ion conducting systems. Several types of lithium ion conducting polymer electrolytes have been prepared as perfect homogenous mixtures of the components, namely, PEO as the polymer matrix which is capable of solving different alkali metal salts, and lithium trifluoromethanesulfonate $\left(\mathrm{LiCF}_{3} \mathrm{SO}_{3}\right)$, lithium tetrafluoroborate $\left(\mathrm{LiBF}_{4}\right)$ and lithium perchlorate $\left(\mathrm{LiClO}_{4}\right)$ as a lithium salt [8]. However, these electrolytes show satisfactory ionic conductivity only at temperatures above $70^{\circ} \mathrm{C}$. The conventional belief has been that the high degree of local order ('crystallinity') is what makes the ionic conductivity too low at ambient temperatures. Therefore, much attention has been devoted to the task of increasing the amorphous content of the PEO electrolyte; either by using large-anion lithium salts, by adding liquid plasticizers or ceramic fillers to the polymer [9-12]. When the electrolytic component is in the form of a dry polymer matrix, it consist of a high molecular weight homo or copolymer, which is cross-linkable or non-cross-linkable and includes a heteroatom in its repeating unit such as oxygen or nitrogen for example, in which an

\footnotetext{
*Corresponding author, e-mail: atillag@marmara.edu.tr (C) BME-PT
} 
alkali metal salt is dissolved such as $\mathrm{LiCF}_{3} \mathrm{SO}_{3}$, $\mathrm{LiClO}_{4}$, LiTFSI etc. In the literature, ion-conducting polyimide membranes are selected as promising candidates for separating the electrodes because such a membrane has the mechanical stability to prevent shorts on rough handling, the chemical stability to prevent decomposition reactions that organic liquid electrolytes are prone to suffer at elevated temperatures, and the ability to resist penetration of lithium dendrites [13]. In the literature, there are only a few studies similar to the work that has been carried out by several research groups [14-22]. For instance, U.S. Patent 5888672 issued to Gustafson and Antonucci [14] disclosure a battery wherein each of the anode, cathode and electrolyte layer is based upon soluble, amorphous and thermoplastic polyimide. In another study, Johnson et al. [15] explored to comprise a solid, thermoset polyimide matrix doped with a lithium salt (LiTFSI). Wensley prepared several optically clear polyimide based electrolytes and determined the minimum required amount of lithium per mole of imide ring in soluble polyimide for rechargeable batteries [16]. The aim of the present work is to investigate the effects of Li-salt and PEO on the ionic conductivity and morphological behavior of PI based polymer electrolyte.

\section{Experimental}

\subsection{Materials}

3,3',4,4'-Benzophenone tetracarboxylic dianhydride (BTDA, Aldrich, Steinheim-Germany), 4,4'Oxydianiline (ODA, Aldrich, Steinheim-Germany), Poly(ethylene oxide) (average $M_{\mathrm{w}}=100.000 \mathrm{~g} \cdot \mathrm{mol}^{-1}$, powder, Aldrich, Steinheim-Germany), Lithium trifluoromethanesulfonate $\left(\mathrm{LiCF}_{3} \mathrm{SO}_{3}, 99.995 \%\right.$ Aldrich, Steinheim-Germany), Dimethylacetamide (DMAc, Aldrich, Steinheim-Germany) were dried under vacuum before being used and stored in home-designed glove box (Ercom Kompresör, Kartal/İstanbul, Turkey) until use.

\subsection{Preparation of lithium salt containing polyimide membrane}

ODA and DMAc were placed into a $100 \mathrm{~mL}$ threeneck flask under nitrogen purge. The mixture was stirred until the solution was clear. BTDA in equal molar amount to that of ODA was added to the solution and stirred for $24 \mathrm{~h}$ at room temperature to give a viscous, transparent and yellow solution of
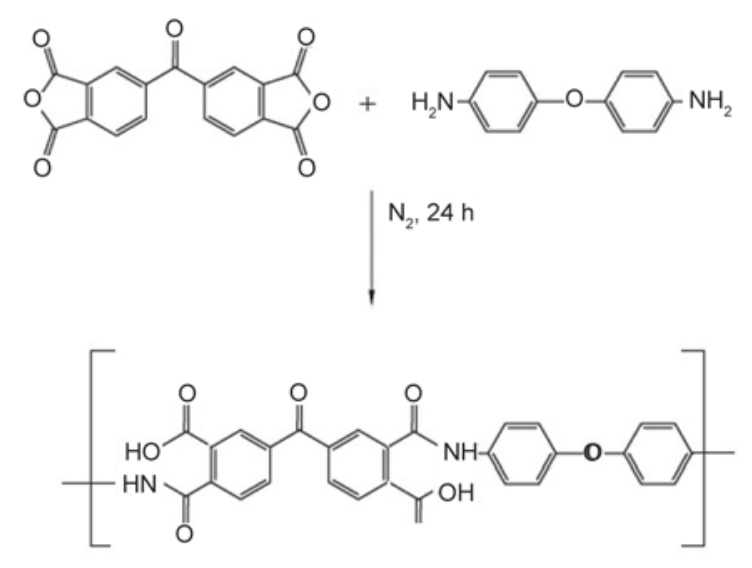

BDTA-ODA based PAA

Figure 1. Shematic representation of synthesis BTDAODA based PAA

PAA (Figure 1) which afforded approximately $20 \%$ solid by weight. PAA solutions containing different amounts of $\mathrm{LiCF}_{3} \mathrm{SO}_{3}$ salt were converted to polyimide by thermal imidization technique heating one hour each at $80-100-150-200-250^{\circ} \mathrm{C}$ ranges applied onto glass plates (F1-F4) (Figure 2). Polyimides having long PEO moieties in the main chain (F5 and F6) have been prepared by heating overnight at relatively low temperatures to prevent the degradation of polyether chain $\left(\approx 150^{\circ} \mathrm{C}\right)$.

\subsection{Characterization}

FT-IR spectrum was recorded on Perkin Elmer Spectrum 100 ATR-FTIR spectrophotometer (Perkin Elmer, Waltham, MA, USA). SEM imaging of the films were performed on Philips XL30 ESEM-FEG/ EDAX (Philips, Eindhoven, The Netherlands). The specimens were prepared for SEM by freeze fracturing in liquid nitrogen and applying a gold coating. The thermal stability of the samples was tested in the temperature range of $30-800^{\circ} \mathrm{C}$ by thermogravimetric analysis (TGA) using a PerkinElmer STA 6000 instrument (PerkinElmer, Waltham, MA, USA) under air atmosphere at a heating rate of $10^{\circ} \mathrm{C} / \mathrm{min}$. Differential scanning calorimetry (DSC) measurements were carried out with a Perkin Elmer Pyris Diamond (PerkinElmer, Shelton, CT, USA). The samples were analyzed under a nitrogen atmosphere in the temperature range -100 to $400^{\circ} \mathrm{C}$ at a heating rate of $10^{\circ} \mathrm{C} / \mathrm{min}$ and cooling rate of $100^{\circ} \mathrm{C} / \mathrm{min}$. Standard tensile stress-strain experiments were performed at room temperature on a Materials Testing Machine Z010/TN2S (Zwick GmbH\&Co. KG, Ulm, Germany) using a crosshead speed of $5 \mathrm{~mm} \cdot \mathrm{min}^{-1}$. The mechanical properties of 


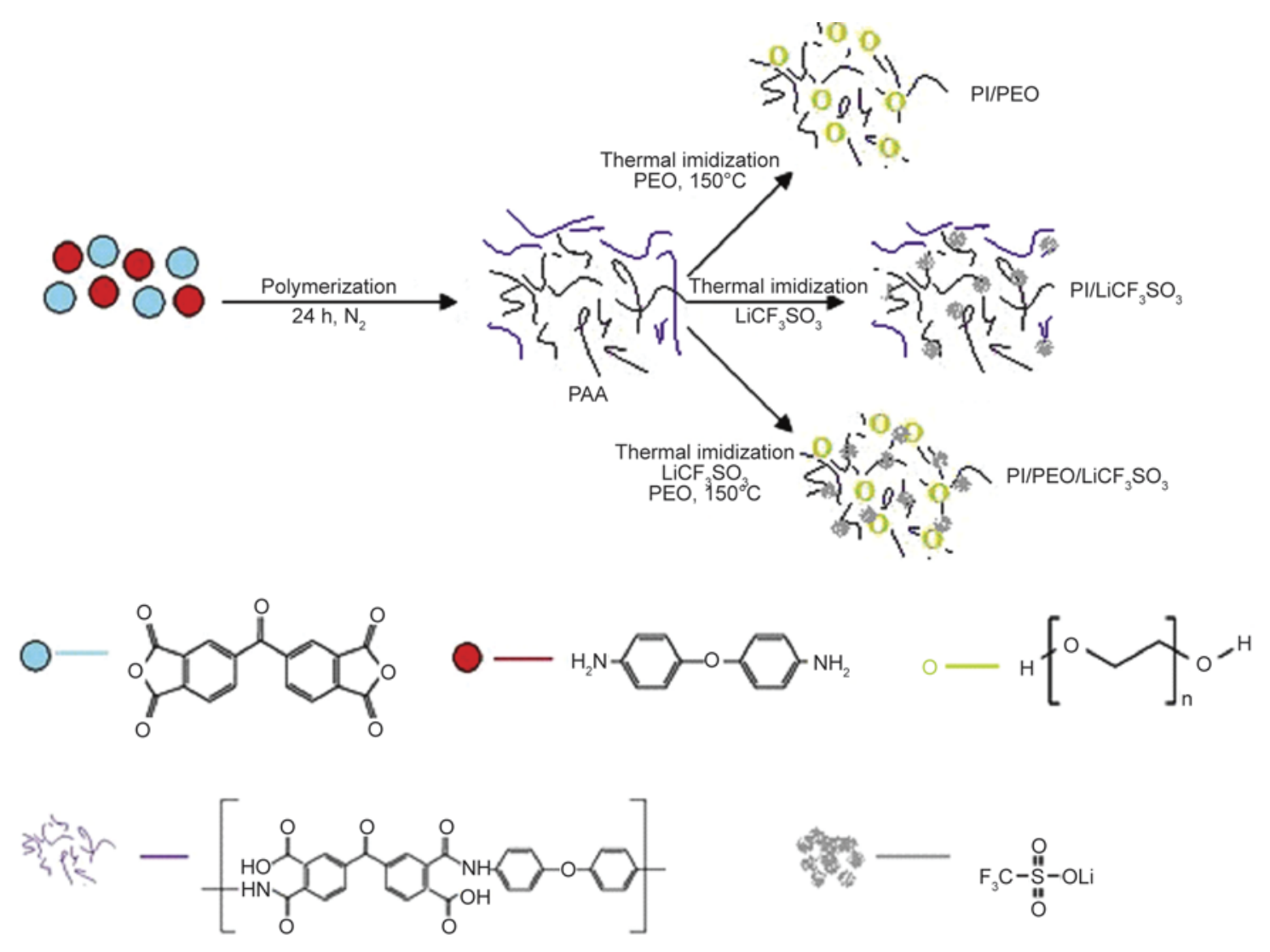

Figure 2. Shematic representation of preparation of Li-salt-doped polyimide membrane

the PI based polymer electrolytes were determined by standard tensile stress-strain tests in order to measure tensile strength and elongation at break. The specimen dimensions were $60.00 \mathrm{~mm}$ in length and $8.00 \mathrm{~mm}$ in width. Four parallel measurements were carried out for each sample.

Ionic conductivity measurements were recorded using a Gamry Potentiostat/Galvanostat/ZRA (Gamry Series G 750, Warminster, PA, USA) with Gamry Framework software system EIS300. EIS spectra were analyzed using Echem Analyst 5.67 software. The polymer electrolyte (PE) was placed between two SS (type 304, $0.025 \mathrm{~mm}$ thick, Alfa Aesar, Karlsruhe, Germany) electrodes in a cell. The thickness of the membrane was measured before and after the EIS measurement, to assure a constant thickness throughout the experiment. Ionic conductivity was measured under an argon atmosphere using a potantiostat/galvanostat and a home-design glove box with conductivity cell. The frequency ranged from $40 \mathrm{~Hz}$ to $100 \mathrm{mHz}$ at a perturbation voltage of $5 \mathrm{mV}$. The ionic conductivity values of the polymer electrolyte systems are calculated from the intercept of real part of the complex impedance plot, which is resistance of the film and known area using the Equation (1) $[19,20]$ :

$\sigma=\left(\frac{1}{R}\right) \cdot\left(\frac{L}{A}\right)$

where $\sigma$ is conductivity; $L / A$ is geometrical factor, $L$ is the thickness of the electrolyte film; $R$ is resistance of the electrolyte film; and $A$ is the area of the film.

Linear Sweep Voltammetry (LSV) measurement was recorded using a Gamry Potentiostat/Galvanostat/ ZRA (Gamry Series G 750, Warminster, PA, USA) with Gamry Framework Software System PHE200 (Physical Electrochemistry Software, Warminster, PA, USA). LSV experiment was performed to investigate the electrochemical stability window of the polymer electrolyte (F5) employing SS as working electrode and lithium foil (Sigma-Aldrich, Steinheim-Germany) as reference and counter electrodes. Cell assembly was carried out in argon atmosphere inside the glove box. The scanning rate was $1 \mathrm{mV} \cdot \mathrm{s}^{-1}$ and the potential ranged from open circuit potential to $5.0 \mathrm{~V}$ (vs. $\mathrm{Li} / \mathrm{Li}^{+}$). 


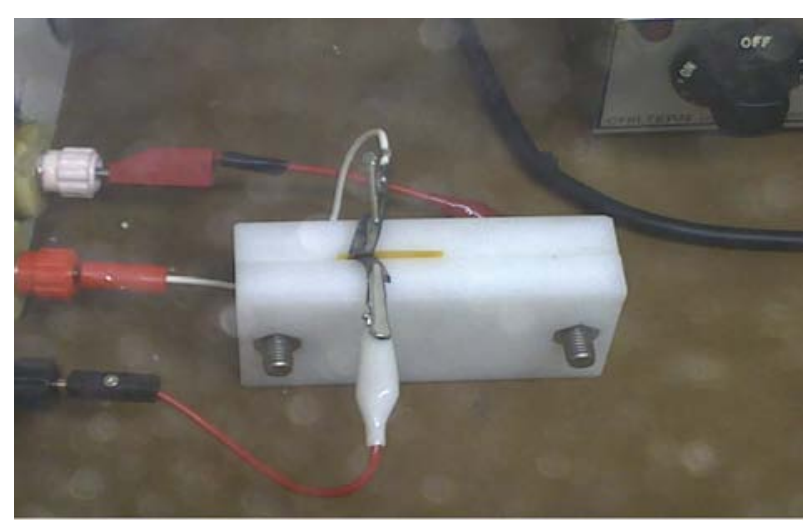

Figure 3. Picture of the conductivity cell

All the electrochemical experiments were carried out in an Argon atmosphere in a home-designed glove box at room temperature (Figure 3).

\section{Results and discussions}

\subsection{FT-IR}

The structures of membranes were investigated by FTIR. To evaluate the molecular interactions between PI and PEO, the FTIR spectrum of pure PEO was also displayed in the insert of Figure 4. Figure 4 shows the FTIR spectra of (a) membrane F0, (b) membrane F1, (c) membrane F5, (d) membrane F6 and (e) pure PEO. In all these work, the complexation is confirmed by the appearance of new peaks, frequency shifts, changes in intensities or shape of existing peaks in the FTIR spectra. The chemical bonding between PEO chain, $\mathrm{LiCF}_{3} \mathrm{SO}_{3}$,

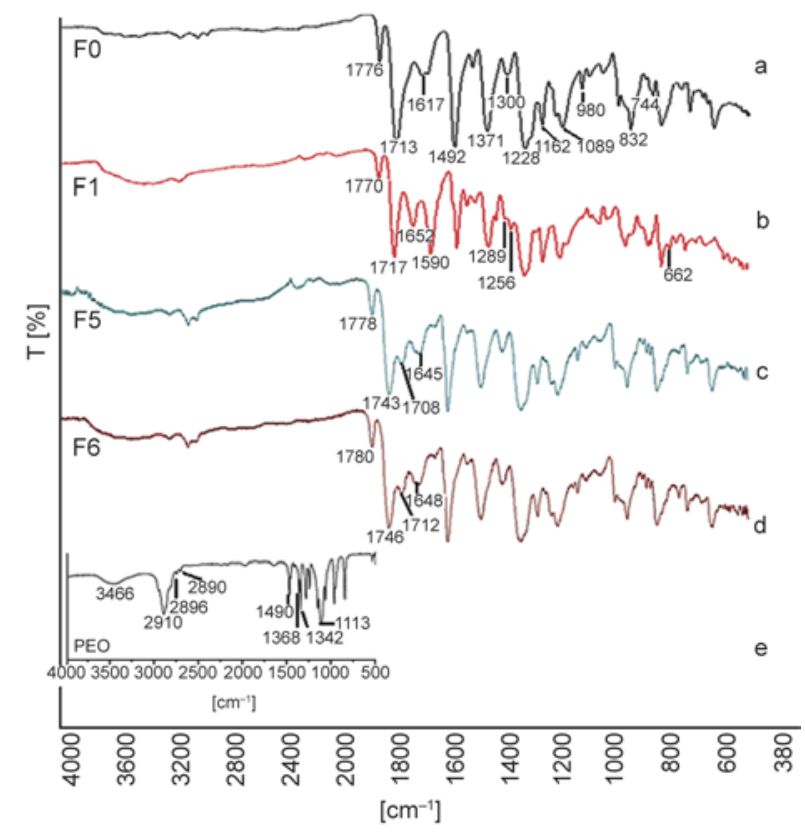

Figure 4. FT-IR spectra of a) PI and b) PI-LiCF $3 \mathrm{SO}_{3}$ c) PI$\mathrm{PEO}$ and d) PI-PEO-LiCF $\mathrm{SO}_{3}$ e) pure PEO
PEO-LiCF $\mathrm{SO}_{3}$ and PI structure was discussed below.

The FT-IR spectroscopy indicated that complexation has occurred between polymer matrix and salt. Figure 4 curve a is FT-IR spectra for polyimide film without the addition of a Li salt or any solvent. The characteristic absorption bands of the imide groups near 1776 (asym. imide carbonyl stretching), 1713 (sym. imide carbonyl stretching) and $1371 \mathrm{~cm}^{-1}$ (imide $\mathrm{C}-\mathrm{N}$ stretching) were observed in the FTIR spectrum after thermal imidization of the poly (amic acid). Meanwhile, the characteristic absorption of the amide carbonyl at $1640 \mathrm{~cm}^{-1}$ did not appear in the spectrum, indicating that the imidization reaction is complete. Strong bands in the range of $1300 \mathrm{~cm}^{-1}$ (imide $\mathrm{C}-\mathrm{N}$ stretching) and $744 \mathrm{~cm}^{-1}$ (imide $\mathrm{C}-\mathrm{H}$ bending) are also observed in the spectrum. Other absorption bands at 1617 and $1492 \mathrm{~cm}^{-1}$ are aromatic $\mathrm{C}=\mathrm{C}$ stretching and benzene ring vibrations, respectively. Moreover, the spectra of membrane F0 show asymmetric stretching ether $(\mathrm{C}-\mathrm{O}-\mathrm{C})$ bands at 1228, 1162 and 1089 and aromatic $\mathrm{C}-\mathrm{H}$ bending bands between 980 to $832 \mathrm{~cm}^{-1}$ [23].

On the other hand, Figure 4 curve $b$ shows FT-IR spectrum of $\mathrm{PI}-\mathrm{LiCF}_{3} \mathrm{SO}_{3}$ membrane. The resulting polyimide electrolyte shows strong peaks at about 1652 and $1590 \mathrm{~cm}^{-1}$. Previously it was reported that, polyimide electrolyte shows a very strong doublet at about 1670 and $1640 \mathrm{~cm}^{-1}$. These peaks are the evidence for the complex between lithium salt and the imide rings of the polyimide [24]. Slight shifts observed in these peaks could be attributed to the use of different salts and different polyimide materials. Also it can be seen that, the characteristic polyimide peaks at 1776 and $1713 \mathrm{~cm}^{-1}$ are shifted to 1770 and $1717 \mathrm{~cm}^{-1}$, respectively. The other bands at 1256 and $1289 \mathrm{~cm}^{-1}$ related sym. $\mathrm{CF}_{3}$ stretching and asymm. $\mathrm{SO}_{3}$ stretching modes. Also the complexation of the $\mathrm{LiCF}_{3} \mathrm{SO}_{3}$ salt with PI was confirmed by the presence of new peak at $662 \mathrm{~cm}^{-1}$ corresponding to free $\mathrm{SO}_{3}{ }^{-}$ion [25]. Furthermore it indicates an interaction/complexation between polyimide material and $\mathrm{Li}$-salt. It is known that $\mathrm{Li}^{+}$ is a very good complex forming species and therefore, it may possibly form some strong coordinate bond with the imide nitrogen atom or the imide carbonyl [26].

As can be seen in Figure 4 curve e, in the pure PEO spectrum a large broad band appears centered at 
$3466 \mathrm{~cm}^{-1}$. Pure PEO shows a large, broad band of $\mathrm{CH}_{2}$ stretching at $2910 \mathrm{~cm}^{-1}$. However, the band is split into two at 2918 and $2884 \mathrm{~cm}^{-1}$ corresponding to asymmetric and symmetric $\mathrm{CH}_{2}$ stretching, respectively [27]. Other bands at 1490, 1368-1342 and $1113 \mathrm{~cm}^{-1}$ are $\mathrm{CH}_{2}$ scissoring, $\mathrm{CH}_{2}$ wagging, $\mathrm{C}-\mathrm{O}-\mathrm{C}$ stretching modes $[28,29]$.

The existence of chemical interchain between PEO with PI was proved by FTIR study. As it can be seen in Figure 4 curves $c$ and d, the band at 1743 and $1746 \mathrm{~cm}^{-1}$ corresponds to the esther carbonyl groups. The presence of ester bonds resulted in a shift of the peak of the imide carbonyl groups at around 1708 (curve c) and $1712 \mathrm{~cm}^{-1}$ (curve d). In these spectra, the peaks at 1645 and $1648 \mathrm{~cm}^{-1}$ were attributed to the amide carbonyl groups due to partially imidization of membranes F5 and F6 which were imidized at low temperatures.

\subsection{Morphology properties of polyimide membranes}

The morphologies of the PI, PI-PEO and their composite polyelectrolyte membranes were studied by scanning electron microscopy (SEM) as shown in Figure 5. As seen in Figure 5a, the fractured surface of the PI membrane is dense and homogeneous. Since the thermal imidization was performed by stepwise heating up to $250^{\circ} \mathrm{C}$, microporosity was not observed on the membrane. However, the surface morphology of the Li salt containing membrane is rough compared with neat PI film as seen in the
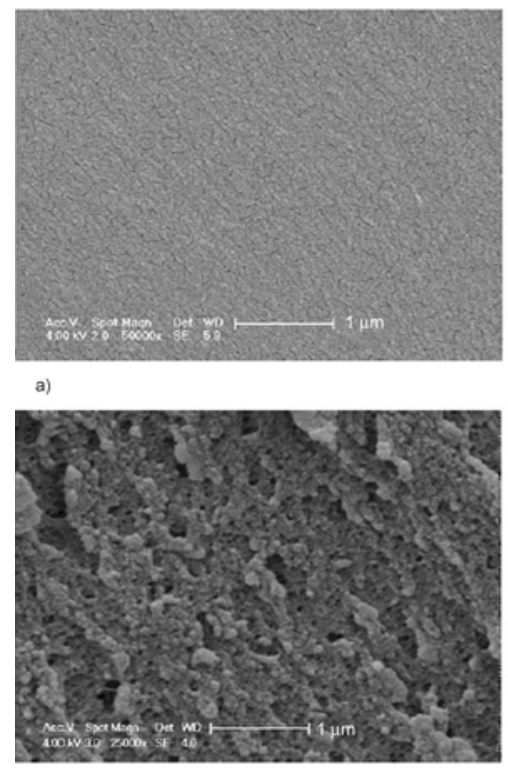

c)
SEM image (Figure 5b). In Figure $5 \mathrm{c}$ the random distribution of PEO structure in PI matrix can be seen. Since the imidization was performed at low temperature to protect the polyether chain from thermal degradation, course voids appeared in the membrane due to the low rate of solvent evaporation. The characteristic semi crystalline morphology of PEO chain was undetectable in the PI-PEO membrane. When only $\mathrm{PEO}$ or $\mathrm{LiCF}_{3} \mathrm{SO}_{3}$ or $\mathrm{PEO} /$ $\mathrm{LiCF}_{3} \mathrm{SO}_{3}$ mixture was incorporated into PI matrix rough morphology was obtained (Figure 5b-5d).

\subsection{Thermal and mechanical properties of polyimide based polymer electrolytes}

Thermo-oxidative stabilities of the polymers were determined by thermogravimetric analysis in air. Figure 6 shows TGA thermograms of polyimides. The dynamic TGA experiments were run from 30 to $800^{\circ} \mathrm{C}$, at a heating rate of $10^{\circ} \mathrm{C} / \mathrm{min}$ under air atmosphere. The first stage of decomposition started at about $250^{\circ} \mathrm{C}$ due to the degradation of organic group of $\mathrm{LiCF}_{3} \mathrm{SO}_{3}$ salt $\left(-\mathrm{CF}_{3}-\mathrm{SO}_{3}\right.$ bridge $)$ and $\mathrm{PEO}$ $(\mathrm{C}-\mathrm{O}-\mathrm{C})$, which were the weakest linkages along the main chain. The second stage of decomposition started from $450^{\circ} \mathrm{C}$ corresponding to the degrading of the aromatic imido groups; this is typical for aromatic polyimides in general [30]. In addition, although PEO decomposition temperature is much lower than polyimide, TGA curves of PEO containing polyimide membranes (F5-F6) have approximately same thermal properties. This result is

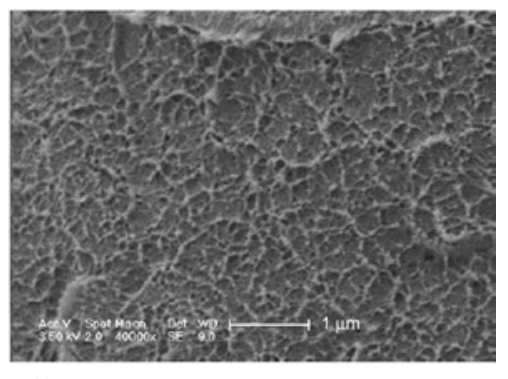

b)

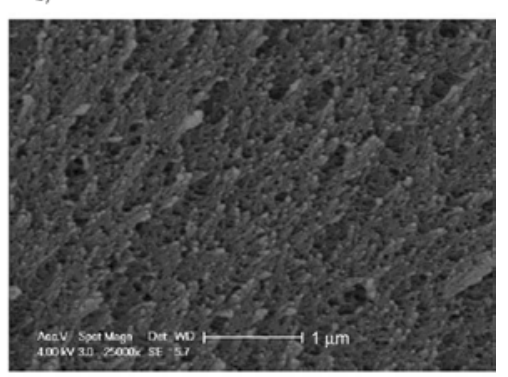

d)

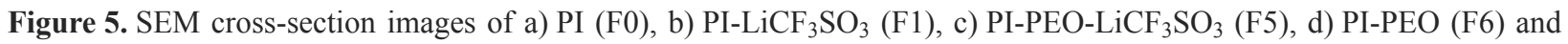
e) pure PEO 
explained by seconder interaction between molecules and also incorporating very low concentrations of PEO.

The TG and derivative thermogravimetric analysis (DTG) curves of PI based membranes under air indicate three stages of thermal decomposition. However, the resulting curve, shown in Figure 6 stable up PI based electrolytes approximately not less than $50 \%$ of their mass, which was illustrated in all of the PI membranes, had excellent stability. The glass transition temperature $\left(T_{\mathrm{g}}\right)$ of neat PI (F0) was found as $297.4^{\circ} \mathrm{C}$. When Li salt was added, the $T_{\mathrm{g}}$ of the composite film decreased to $271.6^{\circ} \mathrm{C}$. Thus, it can be said that the Li salt particles decrease the chain interactions in the PI matrix by settling between polymer chains. On the other hand, in thermal imidization conditions $\left(150^{\circ} \mathrm{C}\right.$ for membranes F5 and F6) when PEO and the Li salt were incorporated into PI matrix, $T_{\mathrm{g}}$ was further reduced to $211.7^{\circ} \mathrm{C}$. Partly remained solvent's effect is related to a weakening of the dipole-dipole interactions between the polymer chains. This result in a reduction of the $T_{\mathrm{g}}$ value. Therefore, this helps to soften the polymer backbone and increase its segmental motion. Relatively, this situation was attributed to the increased free volume at the molecular level due to presence of flexible PEO chains.

It is known that the mechanical properties of the SPEs are as important as the ionic conductivity at room temperature for their practical applications. Elongation at break and tensile strength of polymer electrolyte membranes are displayed in Table 2. For $\mathrm{F} 1$ to $\mathrm{F} 4$ membranes, decreasing Li content in the membrane decreases the elongation and tensile

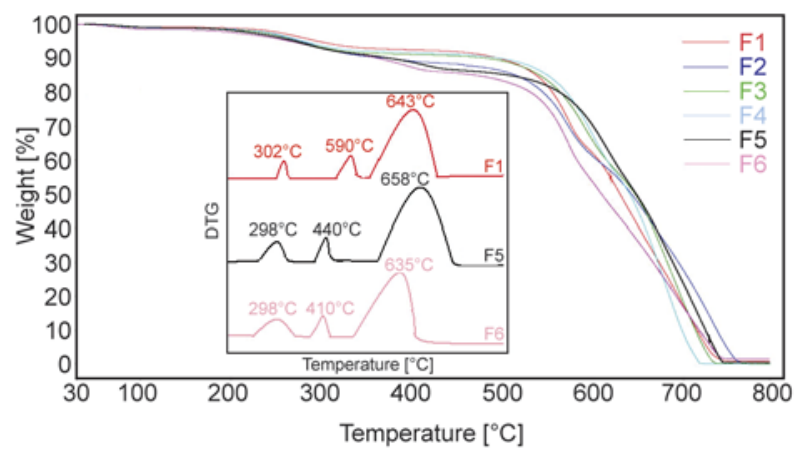

Figure 6. TGA thermograms of F1-F6 films recorded at a heating rate of $10^{\circ} \mathrm{C} / \mathrm{min}$ for the polyimides containing various $\mathrm{PEO}, \mathrm{LiCF}_{3} \mathrm{SO}_{3}$ and $\mathrm{PEO}-$ $\mathrm{LiCF}_{3} \mathrm{SO}_{3}$ contents. Inset Figure: The DTG curve shows stepwise decomposition of F1, F5 and F6 membranes. modules in the same manner. This behaviour was attributed decreasing the level of the hydrogen bond the carbonyl oxygen. When membranes F5 and F6 were compared, it is clearly observable that the addition of Li salt within the PEO containing PI membrane caused negligible changes. When membranes F2 and F5 were compared, it is clearly observable that the addition of PEO causes drastic reduction in the tensile strength and elongation at break. This could be attributed to the etheric structure of PEO. Finally, as can be seen in Table 2, raising the glass transition temperature of polymer electrolytes improves ionic conductivity but leads to a decrease in mechanical properties.

\subsection{Ionic conductivity}

The ionic conductivity of a polymer electrolyte depends on the concentration of ion carriers and on their mobility. The ionic conductivity in polymer electrolytes is assumed to occur by Lewis acid-base interactions between the cations and the polymer solvent. It is also generally accepted that the ionic conduction occurs mainly in the amorphous component of polymer electrolytes above their $T_{\mathrm{g}}$ with the chain segment mobility playing a critical role in the conductivity mechanism [31].

In the case of solvent free polymer electrolytes, the motions of the polymer host are responsible for the ionic mobility; ions move only if polymer segments undergo fairly large-amplitude motions [32-34] related to $T_{\mathrm{g}}$. Polymer electrolytes show fast ionic conduction above their $T_{\mathrm{g}}$ where they are largely comprised of amorphous phases. Thus, a low $T_{\mathrm{g}}$ polymer like PEO (poly (ethylene oxide)); $T_{\mathrm{g}},-50$ to $-57^{\circ} \mathrm{C}$ [35] has become an important polymer for solvent free electrolytes, and amorphization of this polymer is being researched $[36,37]$ as a way to increase its ionic conductivity.

In this study, the conductivity of the polymer electrolyte membranes was calculated from the measured resistance of the film for the known area and thickness of the polymer film. Table 1 and Figure 7 summarize the compositions and Nyquist diagrams of the thermoset PI based polymer electrolytes. Firstly, the ionic conductivity was studied as a function of Li salt concentration within PI matrix (F1F4). As can be seen in Table 1 , the $\mathrm{Li}^{+}$ion conductivity changed according to $[\mathrm{O}] /[\mathrm{Li}]$ ratio where $[\mathrm{O}]$ is the number of mole of oxygen atoms in polyimide structure from membrane F1 to membrane 
Table 1. The conditions, $\mathrm{Li}^{+}$ion conductivity values and $[\mathrm{O}] /[\mathrm{Li}]$ ratios of membranes

\begin{tabular}{|l|c|c|c|c|c|c|}
\hline & F1 & F2 & F3 & F4 & F5 & F6 \\
\hline Metod & $\begin{array}{c}\text { Thermal } \\
\text { imidization }\end{array}$ & $\begin{array}{c}\text { Thermal } \\
\text { imidization }\end{array}$ & $\begin{array}{c}\text { Thermal } \\
\text { imidization }\end{array}$ & $\begin{array}{c}\text { Thermal } \\
\text { imidization }\end{array}$ & $\begin{array}{c}\text { Thermal } \\
\text { imidization }\end{array}$ & $\begin{array}{c}\text { Thermal } \\
\text { imidization }\end{array}$ \\
\hline $\begin{array}{c}\text { Process temperature } \\
{\left[{ }^{\circ} \mathbf{C}\right]}\end{array}$ & $\begin{array}{c}\mathbf{8 0 - 1 0 0 - 1 5 0 -} \\
\mathbf{2 0 0}-\mathbf{2 5 0}\end{array}$ & $\begin{array}{c}\mathbf{8 0 - 1 0 0 - 1 5 0 -} \\
\mathbf{2 0 0 - 2 5 0}\end{array}$ & $\begin{array}{c}\mathbf{8 0 - 1 0 0 - 1 5 0 -} \\
\mathbf{2 0 0}-\mathbf{2 5 0}\end{array}$ & $\begin{array}{c}\mathbf{8 0 - 1 0 0 - 1 5 0 -} \\
\mathbf{2 0 0}-\mathbf{2 5 0}\end{array}$ & $\mathbf{8 0 - 1 0 0 - 1 5 0}$ & $\mathbf{8 0 - 1 0 0 - 1 5 0}$ \\
\hline Codes & $\mathrm{PI} / \mathrm{LiCF}_{3} \mathrm{SO}_{3}$ & $\mathrm{PI} / \mathrm{LiCF}_{3} \mathrm{SO}_{3}$ & $\mathrm{PI} / \mathrm{LiCF}_{3} \mathrm{SO}_{3}$ & $\mathrm{PI} / \mathrm{LiCF}_{3} \mathrm{SO}_{3}$ & $\mathrm{PI} / \mathrm{PEO} / \mathrm{LiCF}_{3} \mathrm{SO}_{3}$ & $\mathrm{PI} / \mathrm{PEO}$ \\
\hline${ }^{*}[\mathrm{O}] /[\mathrm{Li}]$ ratio & $1: 1$ & $2: 1$ & $4: 1$ & $8: 1$ & $1: 1$ & - \\
\hline PEO $[$ mole $]$ & - & - & - & - & $10^{-6}$ & $10^{-6}$ \\
\hline Iomic conductivity $\left[\mathrm{S} \cdot \mathrm{cm}^{-1}\right]$ & $9.2 \cdot 10^{-7}$ & $1.08 \cdot 10^{-6}$ & $4.44 \cdot 10^{-6}$ & $8.7 \cdot 10^{-6}$ & $2.04 \cdot 10^{-5}$ & - \\
\hline
\end{tabular}

*[O] mole number of oxygen atoms is polyimide structure

Table 2. Thermal and mechanical properties of novel PI based thermoset polymer electrolytes

\begin{tabular}{|l|c|c|c|c|}
\hline Sample code & $\begin{array}{c}\text { Tensile strength } \\
{\left[\mathbf{N} / \mathbf{m m}^{\mathbf{2}}\right]}\end{array}$ & $\begin{array}{c}\text { Elongation at break } \\
{[\mathbf{\%}]}\end{array}$ & $\begin{array}{c}\text { Max weight loss temperature } \\
{\left[{ }^{\circ} \mathbf{C}\right]}\end{array}$ & $\begin{array}{c}\text { The glass transition temperature } \\
{\left[{ }^{\circ} \mathbf{C}\right]}\end{array}$ \\
\hline F0 & 130.80 & 5.40 & 668 & 297.4 \\
\hline F1 & 64.53 & 1.07 & 643 & 271.6 \\
\hline F2 & 33.52 & 0.84 & 660 & 231.3 \\
\hline F3 & 17.80 & 0.60 & 659 & 220.8 \\
\hline F4 & 16.64 & 0.42 & 650 & 213.2 \\
\hline F5 & 16.80 & 0.41 & 658 & 211.7 \\
\hline F6 & 17.68 & 0.40 & 635 & 205.8 \\
\hline
\end{tabular}
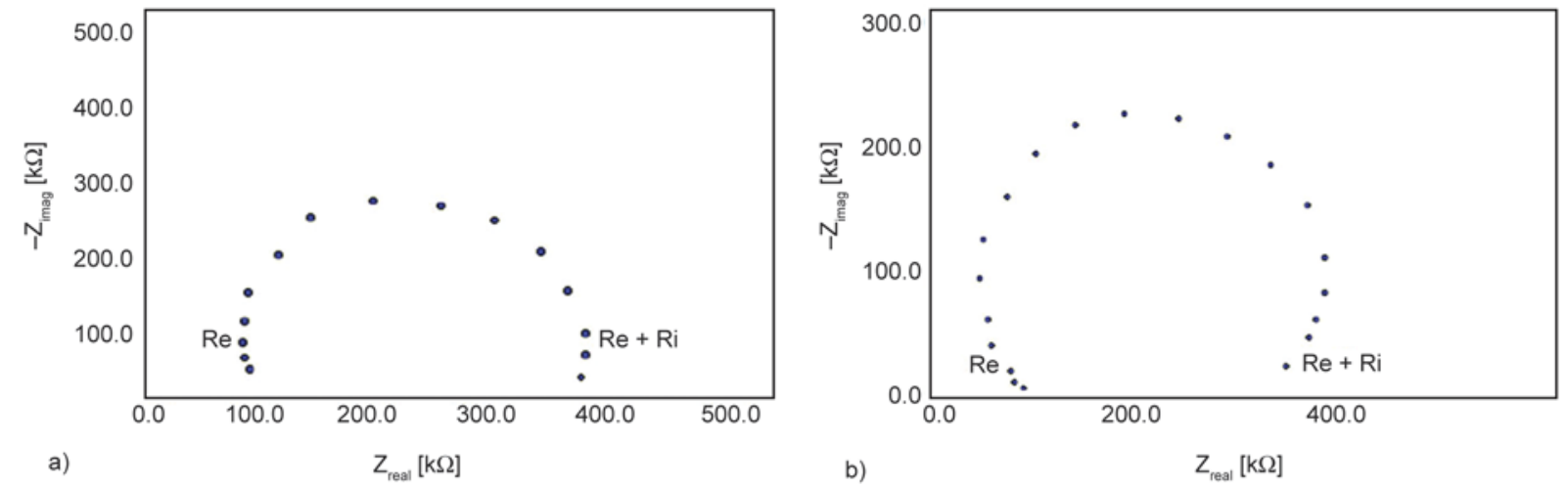

a)

$\mathrm{Z}_{\text {real }}[\mathrm{k} \Omega]$
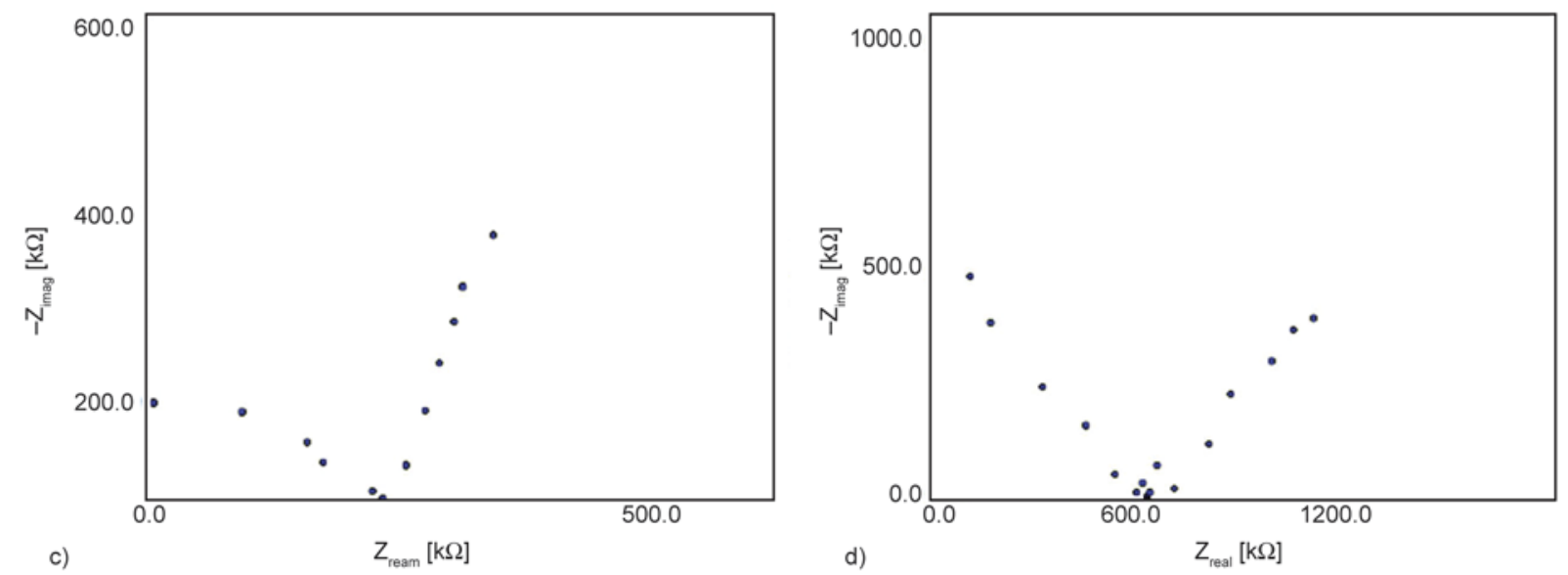

Figure 7. Impedance diagrams of ion-conductive polyimide membranes a) $\mathrm{PI} / \mathrm{PEO} / \mathrm{LiCF}_{3} \mathrm{SO}_{3}(\mathrm{~F} 5)$ b) $\mathrm{PI} / \mathrm{LiCF}_{3} \mathrm{SO}_{3}(\mathrm{~F} 4)$ c) $\mathrm{PI} / \mathrm{LiCF}_{3} \mathrm{SO}_{3}$ (F3) d) $\mathrm{PI} / \mathrm{LiCF}_{3} \mathrm{SO}_{3}$ (F2)

F4. At lower $[\mathrm{O}] /[\mathrm{Li}]$ ratio, ion conductivity significantly decreased. This can be explained by the increased amount of $\mathrm{Li}^{+}$ion concentration in ther- moset polyimide materials which was limited the mobility of polymer chains [24]. In other words, further increase of $\mathrm{Li}$ ion concentration results in 
reduction of conductivity, explained by an increase in transient ionic crosslinks within polymer network, causing a decrease in chain segment mobility. It has also been suggested that at high salt content formation of ion aggregates will contribute to a decrease in conductivity [38]. Hence, membrane F4 showed highest ionic conductivity of $8.7 \cdot 10^{-6} \mathrm{~S} \cdot \mathrm{cm}^{-1}$ compared the other membranes (F1, F2 and F3) at room temperature.

On the other hand, the polymer-salt complexes are formed by complexes between salts of alkali metals and polymer containing solvating heteroatoms such as $\mathrm{O}, \mathrm{N}, \mathrm{S}$, etc. The most common examples are complexation between PEO and alkali metal salts [39]. The ether oxygens in PEO are hard Lewis bases, thus they have low polarizability and high electronegativity. They coordinate well to hard Lewis acids, which in general are small cations, e.g., $\mathrm{Li}^{+1}, \mathrm{Na}^{+1}$ and $\mathrm{Mg}^{+2}$. These cations then, in turn, form salts with low lattice energies together with large, e.g., $\mathrm{PF}_{6}{ }^{-}, \mathrm{CF}_{3} \mathrm{SO}_{3}{ }^{-}$and $\left(\mathrm{CF}_{3} \mathrm{SO}_{3}\right)_{2} \mathrm{~N}^{-}$. These larger anions can sometimes also have a plasticizing effect on the polymer [40]. In addition, the increase in amorphous content is probably due to the large $\mathrm{CF}_{3} \mathrm{SO}_{3}{ }^{-}$anion that reduces the crystallinity of the complex. It can be suggested the increase in conductivity in our system is due to the amorphizing properties of the large $\mathrm{CF}_{3} \mathrm{SO}_{3}{ }^{-}$ion present in the system. The spectroscopically 'free' ions are believed to be responsible for ionic charge transport in polymer electrolyte. They can be temporarily complexed or attached to the polymer chain ( $\mathrm{Li}^{+}$can attach to oxygen atoms on PEO) during segmental motion of the polymer and then hop to the next site. The fraction of 'free' ions will indicate the effectiveness of various electrolyte components in increasing charge concentration and subsequent ion conduction [41]. Thus, the increasing ionic conductivity of PI-PEO-LiCF $\mathrm{SO}_{3}$ film suggested that, even a small amount of PEO added to PI- $\mathrm{LiCF}_{3} \mathrm{SO}_{3}$ membrane, increases the free volume and decreases the $T_{\mathrm{g}}$ which leads to increase molecular mobility. Hence this will cause to increase conductivity. In the PI-PEO-LiCF $\mathrm{SO}_{3}$ electrolyte system (F5) the composition with the highest conductivity is recorded which reaches $2.04 \cdot 10^{-5} \mathrm{~S} \cdot \mathrm{cm}^{-1}$ at room temperature.

\subsection{Linear sweep voltammetry (LSV)}

Electrochemical measurements showed that the cells prepared from using a stainless steel (SS) electrode, a lithium counter, and a lithium reference electrodes had a wide range electrochemical stability. Thus, the high stability of the PI based electrolyte membrane (F5) may be attributed to the absence of impurities, which is a welcome feature because it permits their use in high-voltage battery applications. Figure 8 shows the current-voltage response of the solid polymer membrane obtained in the potential range between open circuit and $5.0 \mathrm{~V}$ vs. $\mathrm{Li}$ at room temperature. As it can be seen, the plateau is very flat and straight; this very low residual current level prior to breakdown voltage, with no peaks in the $2.0-3.5 \mathrm{~V}$ voltage range. So, it confirms the high purity of the SPE membrane was obtained. In addition, the onset of the current during anodic scan, which is representative of the decomposition of the electrolyte, indicates an anodic break-down voltage of approximately $4.3 \mathrm{~V}$ vs. Li. So, membrane F5 showed an appreciable anodic breakdown voltage [42].

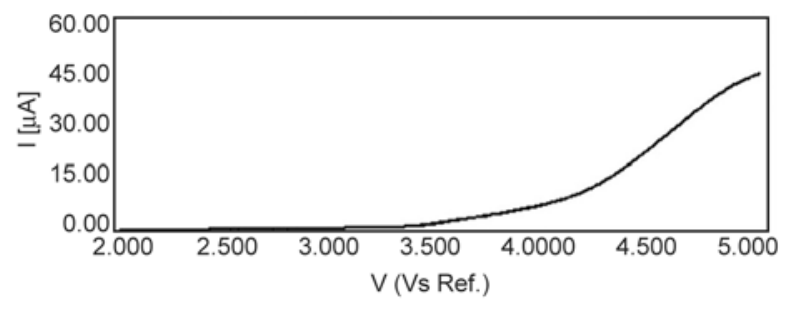

Figure 8. Electrochemical stability window at room temperature for PI based polymer electrolyte (F5), potential scan rate: $1 \mathrm{mV} \cdot \mathrm{s}^{-1}$

\section{Conclusions}

Novel PI-based composite polymer electrolytes were prepared by the incorporation of $\mathrm{LiCF}_{3} \mathrm{SO}_{3}$ and PEO. Characterizations were carried out by FTIR, TGA, DSC, mechanical properties, SEM, impedance measurements and LSV. The thermal imidization technique was adopted to prepare polymer electrolyte membranes. BTDA and ODA based polyimide synthesized by step-growth polymerization method. In order to improve the conductivity behaviour of membranes, we have been focused on introducing the $\mathrm{PEO}$ and $\mathrm{LiCF}_{3} \mathrm{SO}_{3}$ into the polymer backbone. FT-IR measurements showed the 
existence of the complex formation between lithium salt and imide ring of the polyimide. F1 and F5 films showed an ionic conductivity of $9.2 \cdot 10^{-7}$ and $2.04 \cdot 10^{-5} \mathrm{~S} \cdot \mathrm{cm}^{-1}$ respectively at room temperature which is acceptable value for lithium rechargeable batteries. However, this conductivity is still low for practical use in lithium-polymer or lithium-metal batteries. The final solid polymer electrolyte is not soluble in the liquid electrolyte and also stable over a wide range of temperatures.

\section{Acknowledgements}

This work was supported by Marmara University, Commission of Scientific Research Project under grant Project FEN-E-090113-0006.

\section{References}

[1] Critchley J. P., Knight G. J., Wright W. W.: Heat-resistant polymers: Technologically useful materials. Plenum Press, New York (1983).

[2] Mittal K. L.: Polyimides: Synthesis, characterization and applications. Plenum Press, New York (1984).

[3] Bessonov M. T., Koton M. M., Kudryavtsev V. V., Laius L. A.: Polyimides: Thermally stable polymers. Consultants Bureau, New York (1987).

[4] Wilson D., Stenzenberger H. D., Hergenrother P. M.: Polyimides. Blackie, Glasgow (1990).

[5] Ghosh M. K., Mittal K. L.: Polyimides: Fundamentals and applications. Marcel Dekker, New York (1996).

[6] Yamanaka K., Jikei M., Kakimoto M-A.: Preparation and properties of hyperbranched aromatic polyimides via polyamic acid methyl ester precursors. Macromolecules, 33, 6937-6944 (2000).

DOI: $10.1021 / \mathrm{ma} 000725 \mathrm{n}$

[7] Negi Y. S., Suzuki Y-I., Kawamura I., Hagiwara T., Takahashi Y., Iijima M., Kakimoto M-A., Imai Y.: Synthesis and properties of polyimides based on 2,2bis[4-(4-aminophenoxy)phenyl]propane and 2,2-bis [4-(4-aminophenoxy)phenyl]hexafluoropropane. Journal of Polymer Science Part A: Polymer Chemistry, 30, 2281-2284 (1992).

DOI: $10.1002 /$ pola. 1992.080301026

[8] Vallee A., Brouilette D., Pugh J. K., Guindy W. W. J.: Polyimide-based lithium metal battery. U.S. Patent 7824808 B2, USA (2010).

[9] Benrabah D., Sanchez J-Y., Armand M.: Synthesis and electrochemical characterization of a new family of lithium salts. Solid State Ionics, 60, 87-92 (1993). DOI: 10.1016/0167-2738(93)90279-C

[10] Silva M. M., Barros S. C., Smith M. J., MacCallum J. R.: Study of novel lithium salt-based, plasticized polymer electrolytes. Journal of Power Sources, 111, 52-57 (2002).

DOI: $10.1016 / \mathrm{S} 0378-7753(02) 00229-\mathrm{X}$
[11] Croce F., Appetecchi G. B., Persi L., Scrosati B.: Nanocomposite polymer electrolytes for lithium batteries. Nature, 394, 456-458 (1998).

DOI: $10.1038 / 28818$

[12] Reiche A., Weinkauf A., Sander B., Rittig F., Fleischer G.: Alternating copolymers for novel polymer electrolytes: The electrochemical properties. Electrochimica Acta, 45, 1327-1334 (2000).

DOI: $10.1016 / \mathrm{S} 0013-4686(99) 00340-0$

[13] Meyer W. H.: Polymer electrolytes for lithium-ion batteries. Advanced Materials, 10, 439-448 (1998). DOI: 10.1002/(SICI)1521-4095(199804)10:6<439:: AID-ADMA439>3.0.CO;2-I

[14] Gustafson S., Antonucci J. T.: Polyimid battery. U.S. Patent 5888672 A, USA (1999).

[15] Johnson L. G., Allie L. A., Muller J. R.: Solid, lithiumsalt-doped, thermoset polyimide polymer electrolyte and electrochemical cell employing same. U.S. Patent 20130011745, USA (2013).

[16] Wensley C. G., Vallée A., Brouillette D., Gustafson S.: Polyimide matrix electrolyte. U.S. Patent 7198870 B2, USA (2007).

[17] Tigelaar D. M., Palker A. E., Meador M. A. B., Bennett W. R.: Synthesis and compatibility of ionic liquid containing rod-coil polyimide gel electrolytes with lithium metal electrodes. Journal of the Electrochemical Society, 155, 768-774 (2008). DOI: $10.1149 / 1.2967723$

[18] Pak Y. S., Xu G.: Ionic transport measurements of $\mathrm{LiCF}_{3} \mathrm{SO}_{3}$ doped polyimide-diaminobenzenesulfonic acid copolymer. Solid State Ionics, 67, 165-169 (1993). DOI: 10.1016/0167-2738(93)90322-T

[19] Tian S. B., Pak Y. S., Xu G.: Polyimide-polysiloxanesegmented copolymers as high-temperature polymer electrolytes. Journal of Polymer Science Part B: Polymer Physics, 32, 2019-2023 (1994). DOI: $10.1002 /$ polb.1994.090321208

[20] Park J-H., Kim J-S., Shim E-G., Park K-W., Hong Y. T., Lee Y-S., Lee S-Y.: Polyimide gel polymer electrolyte-nanoencapsulated $\mathrm{LiCoO}_{2}$ cathode materials for high-voltage Li-ion batteries. Electrochemistry Communications, 12, 1099-1102 (2010).

DOI: $10.1016 /$ j.elecom.2010.05.038

[21] Gustafson S., Wensley C. G.: Polyimide matrix electrolyte. U.S. Patent 20040229127, USA (2004).

[22] Wensley C. G., Gustafson S., Nelson C. R., Singleton R. W., Vallee A., Brouillette D.: Polyimide matrix electrolyte and improved batteries therefrom. U.S. Patent 7129005, USA (2006).

[23] Davenas J., Xu X. L., Boiteux G. Sage D.: Relation between structure and electronic properties of ion irradiated polymers. Nuclear Instruments and Methods in Physics Research Section B: Beam Interactions with Materials and Atoms, 39, 754-763 (1989).

DOI: $10.1016 / 0168-583 X(89) 90891-4$

[24] Wensley C. G., Vallee A., Brouillette D., Gustafson S.: Polyimide matrix electrolyte. U.S. Patent 7198870 B2, USA (2007). 
[25] de Zea Bermudez V., Alcácer L., Acosta J. L., Morales E.: Synthesis and characterization of novel urethane cross-linked ormolytes for solid-state lithium batteries. Solid State Ionics, 116, 197-209 (1999). DOI: 10.1016/S0167-2738(98)00346-4

[26] Cotton F. A., Wilkinson G.: Advanced inorganic chemistry. Wiley, New York (1988).

[27] Ramesh S., Yuen T. F., Shen C. J.: Conductivity and FTIR studies on PEO-LiX $\left[\mathrm{X}: \mathrm{CF}_{3} \mathrm{SO}_{3}{ }^{-}, \mathrm{SO}_{4}{ }^{2-}\right.$ ] polymer electrolytes. Spectrochimica Acta Part A: Molecular and Biomolecular Spectroscopy, 69, 670-675 (2008).

DOI: $10.1016 /$ j.saa.2007.05.029

[28] Rocco A. M., da Fonseca C. P., Pereira R. B.: A polymeric solid electrolyte based on a binary blend of poly (ethylene oxide), poly(methyl vinyl ether-maleic acid) and $\mathrm{LiClO}_{4}$. Polymer, 43, 3601-3609 (2002).

DOI: $10.1016 / \mathrm{S} 0032-3861(02) 00173-8$

[29] Tang Z., Wang J., Chen Q., He W., Shen C., Mao X-X., Zhang J.: A novel PEO-based composite polymer electrolyte with absorptive glass mat for Li-ion batteries. Electrochimica Acta, 52, 6638-6643 (2007). DOI: 10.1016/j.electacta.2007.04.062

[30] Dhara M. G., Banerjee S.: Fluorinated high-performance polymers: Poly(arylene ether)s and aromatic polyimides containing trifluoromethyl groups. Progress in Polymer Science, 35, 1022-1077 (2010). DOI: $10.1016 /$ j.progpolymsci.2010.04.003

[31] Berthier C., Gorecki W., Minier M., Armand M. B., Chabagno J. M., Rigaud P.: Microscopic investigation of ionic conductivity in alkali metal salts-poly(ethylene oxide) adducts. Solid State Ionics, 11, 91-95 (1983). DOI: $10.1016 / 0167-2738(83) 90068-1$

[32] Wakihara M.: Recent developments in lithium ion batteries. Materials Science and Engineering R: Reports, 33, 109-134 (2001).

DOI: $10.1016 / \mathrm{S} 0927-796 \mathrm{X}(01) 00030-4$

[33] Ratner M. A., Shriver D. F.: Ion transport in solventfree polymers. Chemical Reviews, 88, 109-124 (1988). DOI: $\underline{10.1021 / \mathrm{cr} 00083 \mathrm{a} 006}$
[34] Papke B. L., Ratner M. A., Shriver D. F.: Conformation and ion-transport models for the structure and ionic conductivity in complexes of polyethers with alkali metal salts. Journal of the Electrochemical Society, 129, 1694-1701 (1982).

DOI: $10.1149 / 1.2124252$

[35] Brandup J., Immergut E. H., Grulke E. A., Abe A., Bloch D. R.: Polymer handbook. Wiley, New York (1999).

[36] Le Nest J. F., Callens S., Gandini A., Armand M.: A new polymer network for ionic conduction. Electrochimica Acta, 37, 1585-1588 (1992).

DOI: 10.1016/0013-4686(92)80116-4

[37] Nishimoto A., Watanabe M., Ikeda Y., Kohjiya S.: High ionic conductivity of new polymer electrolytes based on high molecular weight polyether comb polymers. Electrochimica Acta, 43, 1177-1184 (1998). DOI: $10.1016 / \mathrm{S} 0013-4686(97) 10017-2$

[38] Angell C. A., Xu K., Zhang S-S., Videa M.: Variations on the salt-polymer electrolyte theme for flexible solid electrolytes. Solid State Ionics, 86, 17-28 (1996). DOI: 10.1016/0167-2738(96)00088-4

[39] Chandrasekhar V.: Polymer solid electrolytes: Synthesis and structure. Advances in Polymer Science, 135, 139-205 (1998).

DOI: 10.1007/3-540-69191-X_2

[40] Armand M., Gorecki W., Andreani R.: Perfluorosulphonimide salts as solute for polymer electrolytes. in 'Second International Symposium on Polymer Electrolytes' (ed.: Scrosati B.) Elsevier, London, 91-97 (1990).

[41] Tang C., Hackenberg K., Fu Q., Ajayan P. M., Ardebili H.: High ion conducting polymer nanocomposite electrolytes using hybrid nanofillers. Nano Letters, 12, 1152-1156 (2012). DOI: $10.1021 / \mathrm{n} 1202692 \mathrm{y}$

[42] Appetecchi G. B., Croce F., Dautzenberg G., Mastragostino M., Ronci F., Scrosati B., Soavi F., Zanelli A., Alessandrini F., Prosini P. P.: Composite polymer electrolytes with improved lithium metal electrode interfacial properties I. Elechtrochemical Properties of Dry PEO-LiX. Journal of the Electrochemical Society, 145, 4126-4132 (1998).

DOI: $10.1149 / 1.1838925$ 